\title{
Incidence of Rotavirus Among Children with Diarrhoea Attending Hasiya Bayero Pediatric Hospital, Kano State, Nigeria
}

\section{Suleiman Kafilat Olayemi* and Usman Aliyu Dutsinma}

Department of Microbiology, Faculty of Life Science, Bayero University, Kano, Nigeria

*Corresponding Author: Suleiman Kafilat Olayemi, Department of Microbiology, Faculty of Life Science, Bayero University, Kano, Nigeria.

DOI: 10.31080/ASMI.2020.03.0506
Received: January 06, 2020

Published: February 08, 2020

(C) All rights are reserved by Suleiman Kafilat

Olayemi and Usman Aliyu Dutsinma.

\begin{abstract}
Rotavirus is the most common cause of diarrhoeal disease among infants and young children. It is a genus of double-stranded RNA viruses in the family Reoviridae. According to literatures, nearly every child in the world is infected with rotavirus at least once by the age of five. The study was carried out to determine the incidence of Rotavirus among children ( 0 - 5years) suffering from diarrhoea attending Hasiya Bayero Pediatric Hospital, Kano state. Two hundred and ninety-nine children within ages 0 - 5 years who were at Hasiya Bayero Pediatric Hospital, Kano, at the time of the study were enrolled in the study. Diarrhoea samples were obtained following parental consent and ethical approval from the medical research ethics committee of the hospital. The stool samples were collected aseptically in sterile commercial stool containers adequately labeled (patient ID and date of collection) and were transported in ice to the Center for Biotechnology Research, Bayero University Kano where they we restored at $-200 \mathrm{C}$ until tested. The presence of Rotavirus was detected using RDT and ELISA (IgM) in the stool samples. Rotavirus (IgM) was detected in 22 of the 299 subjects giving an incidence of $7.4 \%$ using ELISA. The RDT kit detected Rotavirus in 45 of the 299 subjects giving an incidence of $15.1 \%$. Female subjects had higher incidence (51.1\%) compared to male subjects (48.9\%). Subjects in age group 13-24 months old had the highest incidence of Rotavirus (5.0\% and 3.7\%) while subjects in age group 25 - 36 months old had the lowest percent positive $(0.7 \%$ and $0.3 \%$ ) for RDT and ELISA respectively. The socio-demographic variables associated with the incidence of Rotavirus in this study were mother's level of education, breastfeeding practices and method of water storage. ELISA test kit was found to be more specific and sensitive when compared with Rapid test kit used in this study in detecting Rotavirus. It is recommended that mothers should be educated through their anti-natal and post-natal clinics on the process of avoiding the infection through effective hygiene especially when babies are between 0-5years old especially 13 - 24 months and the detection of Rotavirus among diarrhoea patients should focus more on the use of ELISA instead of RDT.

Keywords: Rotavirus; Diarrhoea; Children
\end{abstract}

\section{Abbreviations}

ELISA: Enzyme Linked Immunosorbent Assay; RDT: Rapid Diagnostic Test; RNA: Ribonucleic Acid

\section{Introduction}

Rotavirus is the most common cause of diarrhoeal disease among infants and young children [1]. It is a genus of doublestranded RNA viruses in the family Reoviridae. Nearly every child in the world is infected with rotavirus at least once by the age of five [2]. Immunity develops with each infection, so subsequent infections are less severe; adults are rarely affected [3]. There are nine species of this virus, referred to as A, B, C, D, E, F, G, H and I. Rotavirus A, the most common species, causes more than $90 \%$ of Rotavirus infections in humans.

The virus is transmitted by the faecal-oral route. It infects and damages the cells that line the small intestine and causes gastroen- teritis (which is often called "stomach flu" despite having no relation to influenza). Although Rotavirus was discovered in 1973 by Ruth Bishop and her colleagues by electron micrograph images [4] and accounts for approximately one third of hospitalizations for severe diarrhoea in infants and children [5]. In addition to its impact on human health, Rotavirus also infects animals, and is a pathogen of livestock [6].

In the United States, before initiation of the Rotavirus vaccination programme, Rotavirus caused about 2.7 million cases of severe gastroenteritis in children, almost 60,000 hospitalizations, and around 37 deaths each year [7]. Following Rotavirus vaccine introduction in the United States, hospitalization rates have fallen significantly [8,9]. Public health campaigns to combat Rotavirus focus on providing oral rehydration therapy for infected children and vaccination to prevent the disease [10]. The incidence and severity of Rotavirus infections has declined significantly in countries that 
have added Rotavirus vaccine to their routine childhood immunization policies [11-13].

\section{Statement of research problem}

Rotavirus infections have been recognized as a common cause of acute gastroenteritis in humans and animals and are the most important cause of severe dehydrating diarrhoea in young children in both developed and developing countries $[14,15]$. Rotavirus is highly communicable, with a small infectious dose of less than 100 virus particles [16]. It is shed in the stool at high concentration and transmission is through faecal-oral route, either person-to-person or through fomites in the environment. Rotavirus is common, accounting for $35-60 \%$ of acute severe diarrhoea in children $<5$ years of age in countries without rotavirus vaccine, with the highest attributable percentage in infants [17]. Rotavirus diarrhoea is ubiquitous and, unlike bacterial diarrhoea, is not more prevalent in settings with poor water, sanitation and hygiene. Rotavirus has a case-fatality rate (CFR) of approximately $2.5 \%$ among children in developing countries who present to health facilities [17]. Rotavirus infection is not routinely diagnosed in most Nigerian hospitals probably due to the cost of the diagnosis and the clinical spectrum of signs and symptoms are similar to other gastroenteritis. Also, certain environmental, climatic, sanitary and behavioral factors are associated with the infection.

\section{Justification}

Due to lack of information on the epidemiology and genetic characteristics of the circulating human Retrovirus in most of the developing nations of which Nigeria is not an exception there is therefore need for researchers to intervene in finding lasting solution. This will be crucial to guide control and prevention strategies so as to ensure that Rotavirus infection is reduced.

The aim of this study was to determine the incidence of Rotavirus among children suffering from diarrhoea attending Hasiya Bayero Pediatric Hospital, Kano state.

The objectives of the research are:

1. To detect of Rotavirus among children suffering from diarrhoea by Rapid Diagnostic Test (RDT).

2. To determine the occurrence of Rotavirus Immunoglobulin M (IgM) among children suffering from diarrhoea.

3. To establish the relationship between socio-demographic factors and Rotavirus infection in children ( $0-5$ years) with diarrhoea.

\section{Materials and Methods}

Study area

The study was conducted at the Center for Biotechnology Research, Bayero University Kano.

\section{Study design}

This cross sectional study included children under five years with diarrhea attending Hasiya Bayero Pediatric Hospital and the incidence of Rotavirus among diarrhoeic children was established.

\section{Study population}

Study population involved children under five years with diarrhoea at Hasiya Bayero Pediatric that had not taken antimicrobial drugs. Information regarding sex, age, onset of diarrhoea and other relevant clinical information were obtained. Diarrhoea case was defined as three or more liquid or semi-liquid stool defecation per day. Sex matched concurrent healthy children who had no diarrhoea complain during previous month and were not on antimicrobial drugs for 1 week were included in this study as control group.

\section{Sample size determination}

The prevalence of Rotavirus among children of 5 years and below with diarrhoea in Sokoto state has been hypothesized to be approximately $25.5 \%$ (Alkali., et al. 2016). To obtain the same prevalence with an error of $5 \%$ and $95 \%$ confidence level, the minimum estimated sample size was 292 using Open EPI V. 2.3 although 299 samples were collected.

\section{Sample collection}

Diarrhoea samples were collected from diarrhoeic children less than 5 years of age presented at the study hospital. The samples were obtained following parental consent and ethical approval from the medical research ethics committee of the hospital. The stool samples were collected aseptically in sterile commercial stool containers adequately labeled (patient ID and date of collection) and were transported in ice to the Center for Biotechnology Reasearch, Bayero University Kano where they we restored at -200C until tested.

\section{Preparation of $10 \%$ stool suspension}

The stored stool specimens were retrieved after freeze thawing and a $10 \%$ stool suspensions were prepared by pipetting $1.5 \mathrm{~mL}$ of supply specimen preparation buffer (included in the kit).

\section{Rapid diagnostic test (RDT)}

Stool samples collected from diarrhoeic children were tested using Feacal Rotavirus Antigen Rapid Test Kit by which the cap of the specimen collection tubes were unscrewed and then the collection applicators were swabbed into the feacal specimens in 3 places to collect about $50 \mathrm{mg}$ of feaces. The caps were then tightened onto the specimen collection tubes and shook vigorously to mix the specimen with the extraction buffer. The pouches were brought to room temperature before opening as they were stored in a refrigerator at $20^{\circ} \mathrm{C}$ and used within one hour. The specimen collection tubes were held upright, unscrewed and inverted and 2 drops of the extracted specimen was dropped onto the specimen wells of the test devices 
the timer was started and the result was read after 10 minutes of dispensing the specimen. Where two distinct red lines appeared on the test device, one on the control line region (C) and one on the test line region (T) was recorded as positive (+). The intensity of the red line in the test line region varied from one test device to the other indicating the concentration of Rotavirus antigen in the specimen. Therefore, any shade of red color in the test line region was considered positive. Where one line appeared at the control line region (C) and no line at the test line region (T) was recorded as negative $(-)$.

\section{Detection of rotavirus antigen by IgM ELISA}

Rotavirus antigens in stool samples were detected by a commercially available Rotavirus IgM ELISA kit according to the Rotavirus test instructions below:

- $20 \times$ wash solution was prepared by diluting with deionized water 1:20. All standards and samples were added in a micro strip plate before transferring to the Micro ELISA Strip plate. $50 \mu \mathrm{l}$ positive control and $50 \mu \mathrm{l}$ negative control were separately added to the positive and negative well, $10 \mu \mathrm{l}$ testing samples were added, then $40 \mu \mathrm{l}$ sample diluents was added to testing sample wells. Nothing was added to the blank well.100 $\mu$ l of HRP-conjugate reagent was added to each well, covered with an adhesive strip and incubated for 60 minutes at $37^{\circ} \mathrm{C}$. Each well was aspirated and washed: the process was repeated four times for a total of five washes. Washing was done by filling each well with wash solution $(400 \mu \mathrm{l})$ using a squirt bottle. Liquid was completely removed at each step to ensure good performance. After the last wash, remaining wash solution was removed by decanting. The plate was inverted and blotted against clean paper towels. $50 \mu \mathrm{l}$ of chromogen solution A and50 $\mu$ l chromogen solution $B$ were added to each well, gently mixed and incubated for 15 minutes at $37^{\circ} \mathrm{C}$ and protected from light. $50 \mu$ l Stop Solution was added to each well. The color in the wells changed from blue to yellow. The optical density (O.D.) was read at $450 \mathrm{~nm}$ using a micro titer plate reader within 15 minutes.

Identification of rotavirus among children suffering from diarrhoea by rapid diagnostic Test (RDT)

Of the total number of 299 diarrhoea cases investigated the RDT detected a total of 45 or $15.1 \%$. Table 1 below shows the distribution of the cases by age classification of the subjects.

Positive cases of Rotavirus were more common among the subjects who were between 1 and 12 months old. Of the 45 cases detected from the total 28 were within the age of 1 to 12 months. Subject who were between 13 to 24 months were next in the prevalent rate with 15 out of the 45 cases detected with the RDT. Only 2 cases were found among subjects within the age range of 25 to 36 months and no positive case was detected among subjects above 36 months. In the overall, the RDT detected 45 (15.1\%) positive cases out of the 299 subjects suffering from diarrhoea that were involved in the study.

\begin{tabular}{|l|c|c|c|c|c|c|}
\hline \multirow{2}{*}{ Age range of subjects } & \multicolumn{2}{|c|}{ Positive } & \multicolumn{2}{c|}{ Negative } & \multicolumn{2}{c|}{ Total } \\
\cline { 2 - 7 } & Freq & $\mathbf{\%}$ & Freq & $\mathbf{\%}$ & Freq & \% \\
\hline 1-12months & 28 & 9.4 & 94 & 31.4 & 122 & 40.8 \\
\hline 13-24months & 15 & 5.0 & 113 & 37.8 & 128 & 42.8 \\
\hline 25-36months & 2 & 0.7 & 30 & 10.0 & 32 & 10.7 \\
\hline 37-48months & 0 & 0.0 & 12 & 4.0 & 12 & 4.0 \\
\hline 47-60months & 0 & 0.0 & 5 & 1.7 & 5 & 1.7 \\
\hline Total & 45 & 15.1 & 254 & 84.9 & 299 & 100.0 \\
\hline
\end{tabular}

Table 1: Distribution of Subjects by Incidence of Rotavirus with RDT.

Determination of occurrence of rotavirus immunoglobulin M (IgM) among children suffering from diarrhoea by enzyme linked immunosorbent assay (ELISA)

The positive cases detected with the Enzyme Linked Immunosorbent Assay among the total subjects involved in the investigation are distributed along the age grouping in table 2 .

\begin{tabular}{|l|c|c|c|c|c|c|}
\hline \multirow{2}{*}{ Age range of subjects } & \multicolumn{2}{|c|}{ Positive } & \multicolumn{2}{c|}{ Negative } & \multicolumn{2}{c|}{ Total } \\
\cline { 2 - 7 } & Freq & $\mathbf{\%}$ & Freq & $\mathbf{\%}$ & Freq & \% \\
\hline 1-12months & 10 & 3.3 & 112 & 37.5 & 122 & 40.8 \\
\hline 13-24months & 11 & 3.7 & 117 & 39.1 & 128 & 42.8 \\
\hline 25-36months & 1 & 0.3 & 31 & 10.4 & 32 & 10.7 \\
\hline 37-48months & 0 & 0.0 & 12 & 4.0 & 12 & 4.0 \\
\hline 47-60months & 0 & 0.0 & 5 & 1.7 & 5 & 1.7 \\
\hline Total & 22 & 7.4 & 277 & 92.6 & 299 & 100.0 \\
\hline
\end{tabular}

Table 2: Distribution of Subjects by Incidence of Rotavirus with ELISA.

Of the total subjects involved in the study, the Enzyme Linked Immunosorbent Assay detected 22 positive cases (sample OD $\geq 0.243$ ). For the ELISA detection, subjects within the 13 to 24 months' age range were more and were only followed by those below 13 months. Only one positive case was detected with ELISA among subjects who were between 25 and 36 months. No positive case was detected among subject who were above 36 months in age. In the overall, ELISA confirmed $7.4 \%$ of positive cases of Rotavirus among the subjects.

Relationship between socio-demographic factors and rotavirus infection in children (0-5 years) with diarrhoea

A test of association between incidence of Rotavirus among the subject with diarrhoea and the selected socio-demographic variables of the subjects is presented in table 3 . The table shows the extent of association denoted with chi-square (X2) and level of significance ( $p$-value). 


\begin{tabular}{|l|c|c|c|c|c|c|c|}
\hline \multicolumn{1}{|c|}{ Age of subjects } & \multicolumn{2}{|l|}{ Positive } & \multicolumn{2}{c|}{ Negative } & $\mathbf{X}^{2}$ & df & p-value \\
\hline 1-12months & 28 & 23 & 94 & 77 & 12.018 & 4 & 0.017 \\
\hline 13-24months & 15 & 11.7 & 113 & 88.3 & & & \\
\hline 25-36months & 2 & 6.3 & 30 & 93.8 & & & \\
\hline 37-48months & 0 & 0 & 12 & 100 & & & \\
\hline 47-60months & 0 & 0 & 5 & 100 & & & \\
\hline Total & 45 & 15.1 & 254 & 84.9 & & & \\
\hline Gender & 22 & 13.8 & 138 & 86.3 & .455 & 1 & 0.500 \\
\hline Male & 23 & 16.5 & 116 & 83.5 & & & \\
\hline Female & 45 & 15.1 & 254 & 84.9 & & & \\
\hline Total &
\end{tabular}

Mother's level of education

\begin{tabular}{|l|c|c|c|c|c|c|c|}
\hline No formal Education & 4 & 11.4 & 31 & 88.6 & 8.743 & 3 & 0.033 \\
\hline Primary & 15 & 10.1 & 134 & 89.9 & & & \\
\hline Secondary & 20 & 23.8 & 64 & 76.2 & & & \\
\hline Tertiary & 6 & 19.4 & 25 & 80.6 & & & \\
\hline Total & 45 & 15.1 & 254 & 84.9 & & & \\
\hline
\end{tabular}

Breast Feeding practices

\begin{tabular}{|l|c|c|c|c|c|c|c|}
\hline $\begin{array}{l}\text { Exclusive Breast } \\
\text { Feeding }\end{array}$ & 31 & 21.4 & 114 & 78.6 & 10.383 & 2 & 0.006 \\
\hline $\begin{array}{l}\text { Breast Feeding and } \\
\text { bottle feeding }\end{array}$ & 11 & 12.1 & 80 & 87.9 & & & \\
\hline $\begin{array}{l}\text { Stopped Breast } \\
\text { feeding }\end{array}$ & 3 & 4.8 & 60 & 95.2 & & & \\
\hline Total & 45 & 15.1 & 254 & 84.9 & & & \\
\hline
\end{tabular}

Do you wash your hand after child defecation?

\begin{tabular}{|l|c|c|c|c|c|c|c|}
\hline Yes & 34 & 13.8 & 213 & 86.2 & 1.834 & 1 & 0.176 \\
\hline No & 11 & 21.2 & 41 & 78.8 & & & \\
\hline Total & 45 & 15.1 & 254 & 84.9 & & & \\
\hline
\end{tabular}

Source of drinking water

\begin{tabular}{|l|c|c|c|c|c|c|c|}
\hline Tap & 33 & 15.2 & 184 & 84.8 & 0.876 & 3 & 0.831 \\
\hline Well & 6 & 14.3 & 36 & 85.7 & & & \\
\hline River & 1 & 33.3 & 2 & 66.7 & & & \\
\hline Others & 5 & 13.5 & 32 & 86.5 & & & \\
\hline Total & 45 & 15.1 & 254 & 84.9 & & & \\
\hline
\end{tabular}

Method of water storage

\begin{tabular}{|l|c|c|c|c|c|c|c|}
\hline Open container & 2 & 9.5 & 19 & 90.5 & 7.579 & 2 & 0.023 \\
\hline Jerry can with cover & 28 & 21.5 & 102 & 78.5 & & & \\
\hline Drum with lid & 15 & 10.1 & 133 & 89.9 & & & \\
\hline Total & 45 & 15.1 & 254 & 84.9 & & & \\
\hline Dotal & &
\end{tabular}

Do you treat your water before drinking?

\begin{tabular}{|l|c|c|c|c|c|c|c|}
\hline Yes & 9 & 8.7 & 94 & 91.3 & 4.897 & 1 & 0.027 \\
\hline No & 36 & 18.4 & 160 & 81.6 & & & \\
\hline Total & 45 & 15.1 & 254 & 84.9 & & & \\
\hline
\end{tabular}

Table 3: Test of Association between Incidence of Rotavirus and Socio-demographic Variables of the Mothers.

As revealed in table 3 below, there is a significant association between subjects' ages and the incidence of Rotavirus among the subjects. The observed level of significance is $0.017(\mathrm{p}<0.05)$. As shown in the positive cases, subjects of lower ages were more disposed to positive cases of Rotavirus when they had diarrhoea than those who were above 36months in age. Gender of subjects was not significantly associated with the incidence of Rotavirus among the diarrhoea patients $(p>0.05)$. There was a significant association between incidence of Rotavirus among the subjects and their mothers' levels of education ( $p<0.05$ ). Mothers with higher educational levels tended to have subjects who were more predisposed towards positive cases of Rotavirus that those with mothers of lower educational levels.

The incidence of Rotavirus is significantly associated with the breastfeeding practices adopted by the mothers $(\mathrm{p}<0.05)$. This observation could be associated with the younger ages of the subjects as observed in relation to the test of association between age and the positive cases above. Mothers who have stopped breastfeeding had lower positive cases of Rotavirus than those who were still breastfeeding their infants. There was no significant association between mothers who wash their hand after child defecation and the incidence of Rotavirus among the subjects ( $p>0.05$ ).

The source of drinking water was not significantly associated with the incidence of Rotavirus among the subjects ( $p>0.05$ ). There was significant association between the incidence of Rotavirus and the method used for water storage by the mothers ( $\mathrm{p}<$ 0.05). Positive cases were more common among subjects whose mothers stored their water in Jerry cans with covers and those with drums and lids. Subjects whose mothers treated their drinking water were significantly lower in the incidence of Rotavirus than those whose drinking water was not treated $(\mathrm{p}<0.05)$. This would imply that the type of water given to the child is significantly associated with the incidence of Rotavirus among the subjects. The observations here mean that ages of infants play a significant role in their subjectivity to Rotavirus infection when they have diarrhoea.

Table 4 shows the symptoms manifested by positive cases of Rotavirus detected with the RTA. The expected counts are enclosed in bracket along the observed frequencies in the table.

The table revealed that most positive cases of Rotavirus detected with the Rapid Test Assay were significantly associated with incidence of restlessness, stomach ache, dehydration and sunken eyes of those affected $(p<0.05)$. But some of the positive cases were not significantly associated with symptoms like fever and vomiting $(\mathrm{p}>0.05)$.

Table 5 revealed that most positive cases of Rotavirus detected with the ELISA were significantly associated with incidence of 


\begin{tabular}{|l|c|c|c|c|c|c|}
\hline Signs and symptoms: & Variable options & Positive & Negative & Total & Chi-Square & p-value \\
\hline \multirow{3}{*}{ Restlessness } & No & $28(12.6)$ & $56(71.4)$ & $84(84.0)$ & $30.543^{\text {a }}$ & 0.000 \\
\cline { 2 - 7 } & Yes & $17(32.4)$ & $198(182.6)$ & $215(215.0)$ & & \\
\cline { 2 - 7 } & Total & $45(45.0)$ & $254(254.0)$ & $299(299.0)$ & & 0.418 \\
\hline Fever & No & $16(13.7)$ & $75(77.3)$ & $91(91.0)$ & $0.656^{\text {a }}$ & 0.400 \\
\hline & Yes & $29(31.3)$ & $179(176.7)$ & $208(208.0)$ & & \\
\hline Stomach ache & Total & $45(45.0)$ & $254(254.0)$ & $299(299.0)$ & & \\
\hline & No & $29(37.5)$ & $220(211.5)$ & $249(249.0)$ & $13.492^{\text {a }}$ & 0.000 \\
\hline & Yes & $16(7.5)$ & $34(42.5)$ & $50(50.0)$ & & \\
\hline Dehydration & Total & $45(45.0)$ & $254(254.0)$ & $299(299.0)$ & & \\
\hline & No & $25(14.9)$ & $74(84.1)$ & $99(99.0)$ & $12.050^{\text {a }}$ & 0.001 \\
\hline & Yes & $20(30.1)$ & $180(169.9)$ & $200(200.0)$ & & \\
\hline Sunken eyes & Total & $45(45.0)$ & $254(254.0)$ & $299(299.0)$ & & \\
\hline & No & $29(41.2)$ & $245(232.8)$ & $274(274.0)$ & $51.128^{\text {a }}$ & 0.000 \\
\hline & Yes & $16(3.8)$ & $9(21.2)$ & $25(25.0)$ & & \\
\hline Vomiting & Total & $45(45.0)$ & $254(254.0)$ & $299(299.0)$ & & \\
\hline & No & $25(24.2)$ & $136(136.8)$ & $161(161.0)$ & $0.062^{\text {a }}$ & 0.803 \\
\hline & Yes & $20(20.8)$ & $118(117.2)$ & $138(138.0)$ & & \\
\hline
\end{tabular}

Table 4: Association of Symptoms with Positive Cases of Rotavirus Detected by RDT.

\begin{tabular}{|c|c|c|c|c|c|c|}
\hline Signs and Symptoms & Options & Positive & Negative & Total & Chi-Square & P-Value \\
\hline \multirow[t]{3}{*}{ Restlessness } & No & $13(6.2)$ & $71(77.8)$ & $84(84.0)$ & $11.295^{\mathrm{a}}$ & 0.001 \\
\hline & Yes & $9(15.8)$ & $206(199.2)$ & $215(215.0)$ & & \\
\hline & Total & $22(22.0)$ & $277(277.0)$ & $299(299.0)$ & & \\
\hline \multirow[t]{3}{*}{ Fever } & No & $7(6.7)$ & $84(84.3)$ & $91(91.0)$ & $0.021^{\mathrm{a}}$ & 0.884 \\
\hline & Yes & $15(15.3)$ & 193(192.7) & $208(208.0)$ & & \\
\hline & Total & $22(22.0)$ & $277(277.0)$ & $299(299.0)$ & & \\
\hline \multirow[t]{3}{*}{ Stomach ache } & No & $15(18.3)$ & $234(230.7)$ & $249(249.0)$ & $3.886^{\mathrm{a}}$ & 0.049 \\
\hline & Yes & $7(3.7)$ & $43(46.3)$ & $50(50.0)$ & & \\
\hline & Total & $22(22.0)$ & $277(277.0)$ & $299(299.0)$ & & \\
\hline \multirow[t]{3}{*}{ Dehydration } & No & $14(7.3)$ & $85(91.7)$ & $99(99.0)$ & $9.992^{\mathrm{a}}$ & 0.002 \\
\hline & Yes & $8(14.7)$ & $192(185.3)$ & $200(200.0)$ & & \\
\hline & Total & $22(22.0)$ & $277(277.0)$ & $299(299.0)$ & & \\
\hline \multirow[t]{3}{*}{ Sunken eyes } & No & $14(20.2)$ & $260(253.8)$ & $274(274.0)$ & $24.303^{\mathrm{a}}$ & 0.000 \\
\hline & Yes & $8(1.8)$ & $17(23.2)$ & $25(25.0)$ & & \\
\hline & Total & $22(22.0)$ & $277(277.0)$ & $299(299.0)$ & & \\
\hline \multirow[t]{3}{*}{ Vomiting } & No & $13(11.8)$ & $148(149.2)$ & 161(161.0) & $0.263^{\mathrm{a}}$ & 0.608 \\
\hline & Yes & $9(10.2)$ & $129(127.8)$ & $138(138.0)$ & & \\
\hline & Total & $22(22.0)$ & $277(277.0)$ & $299(299.0)$ & & \\
\hline
\end{tabular}

Table 5: Association of Symptoms with Rotavirus Positive Cases Detected with ELISA.

restlessness, stomach ache, dehydration and sunken eyes of those affected $(\mathrm{p}<0.05)$. But some of the positive cases were not significant associated with symptoms like fever and vomiting ( $p>0.05)$.

Relationship between Socio-demographic factors and rotavirus infection in children (0-5 years) with Diarrhea based on result from the enzyme linked immunosorbent assay (ELISA).

Table 6 shows the test of association between incidence of Rotavirus among the subject with diarrhea and the selected sociodemographic variables of the mothers by result obtained with the
Enzyme Linked Immunosorbent Assay. The table showed extent of association denoted with chi-square (X2) and level of significance (p-value).

The test with ELISA did not reveal significant association between subjects' ages and the incidence of Rotavirus. The only socio-demographic Variables found to be significantly associated with the incidence of rotavirus were mothers' level of educational attainment and method of water storage used by the mothers ( $p<$ 0.05). Gender, breast feeding practices, washing of child's hand af- 


\begin{tabular}{|c|c|c|c|c|c|c|}
\hline Variables & Variable Options & Positive & Negative & Total & Chi-Square & P-Value \\
\hline \multirow[t]{3}{*}{ Gender } & Male & $10(11.8)$ & $150(148.2)$ & $160(160.0)$ & $0.620^{\mathrm{a}}$ & 0.431 \\
\hline & Female & $12(10.2)$ & $127(128.8)$ & $139(139.0)$ & & \\
\hline & Total & $22(22.0)$ & $277(277.0)$ & $299(299.0)$ & & \\
\hline \multirow[t]{4}{*}{ Breast Feeding } & Exclusive Breast Feeding & $13(10.7)$ & $132(134.3)$ & $145(145.0)$ & $3.902^{\mathrm{a}}$ & 0.142 \\
\hline & $\begin{array}{l}\text { Breast Feeding and bottle } \\
\text { feeding }\end{array}$ & $8(6.7)$ & $83(84.3)$ & $91(91.0)$ & & \\
\hline & Stopped Breast feeding & $1(4.6)$ & $62(58.4)$ & $63(63.0)$ & & \\
\hline & Total & $22(22.0)$ & $277(277.0)$ & $299(299.0)$ & & \\
\hline \multirow{3}{*}{$\begin{array}{l}\text { Do you wash hand for child after } \\
\text { defecation? }\end{array}$} & Yes & $4(3.5)$ & $44(44.5)$ & $48(48.0)$ & $0.080^{\mathrm{a}}$ & 0.778 \\
\hline & No & $18(18.5)$ & $233(232.5)$ & $251(251.0)$ & & \\
\hline & Total & $22(22.0)$ & $277(277.0)$ & $299(299.0)$ & & \\
\hline \multirow[t]{5}{*}{ Mother's level of education } & No formal Education & $1(2.6)$ & $34(32.4)$ & $35(35.0)$ & $8.538^{\mathrm{a}}$ & 0.036 \\
\hline & Primary & $7(11.0)$ & $142(138.0)$ & $149(149.0)$ & & \\
\hline & Secondary & $12(6.2)$ & $72(77.8)$ & $84(84.0)$ & & \\
\hline & Tertiary & $2(2.3)$ & $29(28.7)$ & $31(31.0)$ & & \\
\hline & Total & $22(22.0)$ & $277(277.0)$ & $299(299.0)$ & & \\
\hline \multirow{3}{*}{$\begin{array}{l}\text { Do you wash your hand after child } \\
\text { defecation? }\end{array}$} & Yes & $17(18.2)$ & $230(228.8)$ & $247(247.0)$ & $0.471^{\mathrm{a}}$ & 0.493 \\
\hline & No & $5(3.8)$ & $47(48.2)$ & $52(52.0)$ & & \\
\hline & Total & $22(22.0)$ & $277(277.0)$ & $299(299.0)$ & & \\
\hline \multirow[t]{5}{*}{ Source of drinking water } & Tap & $15(16.0)$ & $202(201.0)$ & $217(217.0)$ & $3.529^{\mathrm{a}}$ & 0.317 \\
\hline & Well & $4(3.1)$ & $38(38.9)$ & $42(42.0)$ & & \\
\hline & River & $1(0.2)$ & $2(2.8)$ & $3(3.0)$ & & \\
\hline & Others & $2(2.7)$ & $35(34.3)$ & $37(37.0)$ & & \\
\hline & Total & $22(22.0)$ & $277(277.0)$ & $299(299.0)$ & & \\
\hline \multirow[t]{4}{*}{ Method of water storage } & Open container & $2(1.5)$ & $19(19.5)$ & $21(21.0)$ & $6.916^{\mathrm{a}}$ & 0.031 \\
\hline & Jerry can with cover & $15(9.6)$ & $115(120.4)$ & $130(130.0)$ & & \\
\hline & Drum with lid & $5(10.9)$ & $143(137.1)$ & $148(148.0)$ & & \\
\hline & Total & $22(22.0)$ & $277(277.0)$ & $299(299.0)$ & & \\
\hline \multirow{3}{*}{$\begin{array}{l}\text { Do you treat your water before } \\
\text { drinking? }\end{array}$} & Yes & $4(7.6)$ & $99(95.4)$ & 103(103.0) & $2.783^{\mathrm{a}}$ & 0.095 \\
\hline & No & $18(14.4)$ & $178(181.6)$ & $196(196.0)$ & & \\
\hline & Total & $22(22.0)$ & $277(277.0)$ & $299(299.0)$ & & \\
\hline \multirow{5}{*}{$\begin{array}{l}\text { What type of Toilet does child } \\
\text { use? }\end{array}$} & Pit & $2(0.4)$ & $4(5.6)$ & $6(6.0)$ & $7.007^{a}$ & 0.072 \\
\hline & Open Toilet & $2(1.8)$ & $23(23.2)$ & $25(25.0)$ & & \\
\hline & Water Closet & $1(0.4)$ & $5(5.6)$ & $6(6.0)$ & & \\
\hline & Others & $17(19.3)$ & $245(242.7)$ & $262(262.0)$ & & \\
\hline & Total & $22(22.0)$ & $277(277.0)$ & $299(299.0)$ & & \\
\hline \multirow[t]{6}{*}{ Age } & 1-12months & $10(9.0)$ & $112(113.0)$ & $122(122.0)$ & $2.604^{\mathrm{a}}$ & 0.626 \\
\hline & 13-24months & $11(9.4)$ & $117(118.6)$ & $128(128.0)$ & & \\
\hline & 25-36months & $1(2.4)$ & $31(29.6)$ & $32(32.0)$ & & \\
\hline & 37-48months & $0(0.9)$ & $12(11.1)$ & $12(12.0)$ & & \\
\hline & 47-60months & $0(0.4)$ & $5(4.6)$ & $5(5.0)$ & & \\
\hline & Total & $22(22.0)$ & $277(277.0)$ & $299(299.0)$ & & \\
\hline
\end{tabular}

Table 6: Test of Association Between Incidence of Rotavirus and Socio-demographic Variables of the Mothers. 
ter defecation, Source of drinking water, treatment of water before drinking and type of toilet child used by the child were not found to be significantly associated with the incidence of Rotavirus among the subjects ( $p>0.05)$.

\section{Discussion of Results}

This study assessed the incidence of Rotavirus among children suffering from diarrhoea and attending Hasiya Bayero Pediatric Hospital, Kano state. From the test analysis of the data collected for the study, Rapid Diagnostic Test (RDT) detected Rotavirus in 45 (15.1\%) positive Rotavirus cases among 299 subjects involved in the study. Compared to the 22 (7.4\%) detected with the Enzyme Linked Immunosorbent Assay (ELISA), the finding is that the RDT gave false positive result as ELISA is more specific and sensitive in its reactions which is in agreements with the study of Moutelikova., et al [18].

Among the infants related factor of incidence found in the study was that the ages of children were significantly associated with positivity of Rotavirus among diarrhoea patients. In this study, subjects below 36 months were prone to infection of the virus than those above the age limit. Among subject above 36 months, no positive case of Rotavirus was detected. This finding is in agreement with the study of Monica and David [19] who reported that human Rotavirus occurs most commonly between 6 and 24 months of age. It is also in line with Dennehy [1] who reported that Rotavirus is the most common cause of diarrhoea disease among infants and young children. This could be as a result of the reduced severity of Rotavirus in older children which could be due primarily to the immunity induced by previous Rotavirus infections. But gender of the subject was not found to be significantly associated with the positivity of the virus among the children suffering from diarrhoea.

Some of the socio-demographic variables related to the mothers of the subjects were found to be significantly associated with the incidence of Rotavirus positivity among infants suffering from diarrhea. Such variables included breastfeeding practices adopted by the mothers, the method used for water storage, whether mothers treated drinking water or not.

Other mother related socio-demographic variables like washing of children' hands after child defecation, source of drinking water, were not found to be significantly associated with the positivity rate of the virus among the subjects.

\section{Conclusion}

The rotavirus incidence among children involved in the study using the RDT was $15.1 \%$. The incidence by ELISA was 7.4\%. ELISA is more effective for identifying Rotavirus among children suffering from diarrhoea due to its specificity and sensitivity.
Incidence of Rotavirus infection among children suffering from diarrhoea is more prone to those within 1 to 3 years age bracket.

External factors significantly associated with incidence of Rotavirus among children include mothers' level of education, breastfeeding practices, the method used for water storage and whether mothers treated drinking water or not.

\section{Recommendations}

Based on the findings of this study, the following recommendations were made:

1. Detection or identification of Rotavirus among diarrhoea patients should focus more on the use of ELISA instead of RDT.

2. There is need to be educating the mothers through their Antinatal and Post-natal clinics on the processes of avoiding the infection through effective hygiene especially when babies are between 0 and 3year.

\section{Bibliography}

1. Dennehy PH. "Rotavirus Infection: A Disease of the Past?". Infectious Disease Clinics of North America 29.4 (2015): 617-635.

2. Bernstein DI. "Rotavirus overview". The Pediatric Infectious Disease Journal 28.3 (2009): S50-S53.

3. Grimwood K and Lambert SB. "Rotavirus vaccines: opportunities and challenges”. Human Vaccines 5.2 (2009): 57-69.

4. Bishop R. "Discovery of Rotavirus: Implications for child health". Journal of Gastroenterology and Hepatology 24.3 (2009): S81-S85.

5. World Health Organization. "Global Rotavirus Sentinel Hospital Surveillance Network" (PDF) (2015).

6. Dubovi EJ and Mac Lachlan NJ. "Fenner's Veterinary Virology (4th ed.)". Boston: Academic Press (2010): 288.

7. Fischer TK., et al. "Hospitalizations and deaths from diarrhea and Rotavirus among children $<5$ years of age in the United States, 1993-2003". Journal of Infectious Diseases 195.8 (2007): $1117-1125$.

8. Leshem E., et al. "Rotavirus Vaccines and Health Care Utilization for Diarrhea in the United States". Pediatrics 134.1 (2014): 15-23.

9. Tate JE., et al. "Uptake, impact, and effectiveness of Rotavirus vaccination in the United States: review of the first 3 years of postlicensure data". The Pediatric Infectious Disease Journal 30 (2011): S56-S60.

10. Diggle L. "Rotavirus diarrhea and future prospects for prevention". British Journal of Nursing 16.16 (2007): 970-974.

11. Giaquinto C., et al. "Summary of effectiveness and impact of Rotavirus vaccination with the oral pentavalent rotavirus vaccine: a systematic review of the experience in industrialized countries". Human Vaccines 7.7 (2011): 734-748. 
12. Jiang V., et al. "Performance of Rotavirus vaccines in developed and developing countries". Human Vaccines 6.7 (2010): 532542.

13. Parashar UD and Tate JE. "Health Benefits of Rotavirus Vaccination in Developing Countries". Clinical Infectious Diseases 62.2 (2016): S91-228.

14. Kapikian AZ., et al. "Rotaviruses". In Fields virology. 4th ed. Philadelphia (PA): Lippincott Williams and Wilkins (2001): 1787-1833.

15. Tate JE., et al. "Global, Regional, and National Estimates of Rotavirus Mortality in Children <5 Years of Age, 2000-2013". Clinical Infectious Diseases 62.2 (2016): S96-105.

16. American Academy of Pediatrics. "Rotavirus infections". In: Pickering L. K, editor. Red Book: 2003 report of the Committee on Infectious Diseases. 26th ed. Elk Grove Village, IL: American Academy of Pediatrics (2003): 534-536.

17. Kotloff KL., et al. "Burden and aetiology of diarrhoeal disease in infants and young children in developing countries (the Global Enteric Multicenter Study, GEMS): a prospective, casecontrol study". Lancet 382.9888 (2013): 209-222.

18. Moutelikova., et al. "Human rotavirus A detection: Comparison of enzymatic immunoassay and rapid chromatographic test with two quantitative RT-PCR assays". Epidemiologie, mikrobiologie, imunologie, Praha: Česká lékařská společnost Jana Evangelisty Purkyně, 67.3 (2018):110-113.

19. Monica and David., et al. Vaccines for Biodefense and Emerging and Neglected Diseases (2009).

\section{Assets from publication with us}

- Prompt Acknowledgement after receiving the article

- Thorough Double blinded peer review

- Rapid Publication

- Issue of Publication Certificate

- High visibility of your Published work

Website: https://www.actascientific.com/

Submit Article: https://www.actascientific.com/submission.php Email us: editor@actascientific.com

Contact us: +919182824667 